\title{
A HISTÓRIA REGIONAL E O BAIXO AMAZONAS: REFLEXÕES SOBRE ENSINO E PESQUISA*
}

\section{Vanice Siqueira de Melo}

Ensino e pesquisa são dimensões da prática docente que estão conectadas. Essa conexão explica-se não somente pelas pesquisas e reflexões que o professor realiza sobre a docência, os métodos de avaliação, a organização dos currículos, os objetivos da aprendizagem, entres outras. A partir da prática em sala de aula, inúmeros pesquisadores escolhem suas temáticas de pesquisa e/ou refletem sobre a historiografia e sua área de pesquisa.

Este texto é, assim, uma reflexão que resultou de uma experiência docente e uma análise de como essa prática está relacionada com a maneira pela qual penso a história e a historiografia da Amazônia colonial. ${ }^{2}$ Refiro-me à experiência de ministrar o componente curricular História da Amazônia I para uma turma do curso de graduação em história da Universidade Federal do Oeste do Pará (Ufopa), localizada na cidade de Santarém, região do Baixo Amazonas. $^{3}$

A organização da disciplina História da Amazônia I deve ter como referencial, primeiramente, o Projeto Político Pedagógico do Curso de Licenciatura em História da Ufopa (PPC). Como base nesse documento, a disciplina precisa contemplar os

\footnotetext{
*DOI - 10.29388/978-65-86678-64-2-0-f.87-100

${ }^{1}$ Licenciada e bacharel em História pela Universidade Federal do Pará (UFPA), mestra em História pela UFPA, doutoranda em História pela UFPA/Universidad Pablo de Olavide (UPO), docente do curso de História da Universidade Federal do Oeste do Pará (Ufopa).

${ }^{2}$ A expressão história da Amazônia colonial corresponde, neste texto, à área do antigo estado do Maranhão e Grão-Pará. Geograficamente, abrange os atuais estados do Amazonas, do Pará, do Amapá, de Rondônia, de Roraima, do Acre, de Tocantins, do Maranhão e do Piauí.

${ }^{3}$ A denominação Baixo Amazonas, utilizada neste texto, é contemporânea. Trata-se de uma expressão usada para se referir a uma região que abarca 12 municípios: Santarém, Alenquer, Óbidos, Almeirim, Belterra, Curuá, Faro, Juruti, Monte Alegre, Oriximiná, Prainha e Terra Santa. Assim, no recorte temporal contemplado pela disciplina História da Amazônia I, a região formada por esses municípios ainda não era denominada Baixo Amazonas. Porém, aqui ela será utilizada para referenciar o espaço que será discutido no texto.
} 
[...] primeiros contatos dos europeus com o universo amazônico. Estruturação e avanço da ocupação luso-brasileira. Configurações econômicas, sociais e políticas na Amazônia colonial. Mundos do trabalho, antes e depois do período pombalino. Conflitos e negociações em torno da adesão do Pará à Independência. Cabanagem. (Ufopa, 2017).

Contudo, além dessas diretrizes, algumas perguntas norteavam a preparação do curso, entre elas: para quem esse curso será ministrado? Nesse sentido, a ideia era incluir no curso História da Amazônia I também as reflexões historiográficas acerca da região do Baixo Amazonas. Trata-se de análises que não estariam desconectadas da ementa apresentada no PPC do curso.

Somado a isso, a breve experiência de pesquisa em Amazônia colonial e, nesse caso, a importância que as reflexões sobre a historicidade dos espaços geográficos adquiriu durante essa experiência de pesquisa, em certa medida, também guiavam o objetivo do curso. Nesse sentido, as reflexões historiográficas sobre o Baixo Amazonas deveriam abarcar, igualmente, análises da construção desse espaço. Pretendia-se, dessa maneira, discutir, em uma perspectiva regional, a ocupação luso-americana no Baixo Amazonas, sem excluir a dimensão desse povoamento para a vasta Amazônia.

Contudo, a historiografia da Amazônia ainda carece de pesquisas que considerem o espaço a partir de suas dimensões históricas, e são escassas as pesquisas regionais acerca do Baixo Amazonas. Nesse sentido, o objetivo deste capítulo é destacar a relevância de pesquisas que analisem o espaço como uma dimensão histórica e a importância de mais produções historiográficas com recortes regionais sobre a Amazônia colonial.

Dessa maneira, primeiramente apresentarei minha trajetória de pesquisa e como o espaço geográfico tornou-se algo central em minhas reflexões. Posteriormente, farei uma breve apresentação sobre a historiografia da Amazônia colonial e, a partir de algumas fontes do Arquivo Público do Estado do Pará, procurarei apresentar a importância das reflexões sobre a constituição dos espaços geográficos e da história regional.

\section{As guerras e as reflexões iniciais sobre a história da Ama- zônia colonial}

O início da pesquisa sobre a Amazônia colonial aconteceu no curso de bacharelado e licenciatura em história na Universidade Federal do Pará (UFPA), na condição de bolsista do Programa de Iniciação Científica (Pibic/UFPA). Ini- 
cialmente, desenvolvi o plano de trabalho "Os 'índios do corso' e a resistência indígena no estado do Maranhão (século XVII)". A pesquisa consistia em estudar as guerras, justas ou não, que ocorreram entre as tropas luso-americanas e os grupos indígenas no estado do Maranhão e Grão-Pará entre 1640 e 1706. A partir do estudo das guerras, o objetivo da pesquisa era analisar a ocupação portuguesa nesse estado e como as populações indígenas agiram durante o avanço do povoamento luso-americano.

Essa pesquisa desdobrou-se em outro plano de trabalho: “As guerras no Cabo do Norte e na fronteira oriental do antigo estado do Maranhão (16801706)". Nesse segundo momento, o objeto da pesquisa continuava sendo as guerras no estado do Maranhão e Grão-Pará. Porém, nesse plano de trabalho, eu estudava apenas os conflitos que ocorreram na capitania do Cabo do Norte, atual Amapá, e na do Maranhão. Acreditava que as diferentes maneiras pelas quais os luso-americanos organizaram a ocupação dessas regiões resultaram em guerras com finalidades e sentidos diversos (Melo, 2008).

Após a conclusão da pesquisa sobre as guerras no Cabo do Norte e na capitania do Maranhão, iniciei um terceiro período nessa trajetória de pesquisa. Nessa ocasião, já como estudante de um curso de pós-graduação, pesquisava os conflitos entre os luso-americanos e os grupos indígenas nas capitanias do Maranhão e do Piauí, também pertencentes ao estado do Maranhão e Grão-Pará, na primeira metade do século XVIII. Ainda que esses conflitos estivessem presentes em todo o estado do Maranhão e Grão-Pará, pela maneira como se desenvolveu a ocupação na fronteira oriental desse estado, no século XVIII as guerras concentraram-se nesse espaço.

As guerras justas constituíam um mecanismo oficial de escravização indígena. Era, portanto, uma política instituída pela Coroa portuguesa para lidar com índios que eram considerados hostis à presença luso-americana. As guerras estavam, portanto, relacionadas com o avanço de fronteira luso-americana. Como lembrou Ângela Domingues, as causas da guerra justa, além de mudarem ao longo da colonização, eram adaptadas à "ideologia da expansão" (Domingues, 2000, p. 17).

Ainda que o objeto de pesquisa fossem as guerras, era fundamental incluir a dimensão espacial na pesquisa, uma vez que esses conflitos estavam relacionados com o avanço da fronteira luso-americana. Assim, a partir da preocupação de analisar a ocupação luso-americana nas capitanias do Maranhão e do Piauí, comecei a dialogar com as ideias de "espaço geográfico", "território", "territorialidade" e "paisagem". 
Com base nessas ideias, analisei como o espaço das capitanias do Maranhão e do Piauí era representado, principalmente nos relatos sobre as guerras, por soldados, religiosos e autoridades que o percorreram, e como essas representações contribuem para analisar o povoamento luso-americano e a ocorrência das guerras entre os índios e os luso-americanos nessas capitanias (Melo, 2017, p. 23-72). Além disso, foi uma experiência de pesquisa que começou a se articular com a história regional. Nesse caso, considero a história regional como uma escolha de um recorte espacial para um objeto de estudo (Viscardi, 1997).

\section{A história da Amazônia, a história regional e o ensino de história}

A experiência de pesquisa, a concepção de história e de educação, a maneira pela qual os professores compreendem o mundo e quem são seus alunos são alguns fatores que influenciam a prática docente e o que será ensinado em uma sala de aula. Dessa maneira, ao pensar um curso de história da Amazônia para ser ministrado em uma universidade situada no oeste do Pará, na região do Baixo Amazonas, eu acreditava que ele deveria ser construído a partir de produção historiográfica que contemplasse não somente uma reflexão acerca da região chamada Amazônia, tomando por base as discussões sobre as relações de trabalho, conquista e ocupação luso-americana, economia e sociedade na Amazônia colonial. Eu pretendia construir um plano de curso que abrangesse, igualmente, a ocupação luso-americana no Baixo Amazonas, historicizando a construção desse espaço.

A importância de discutir com os alunos do curso de graduação como os espaços foram e são construídos e refletir acerca da história regional justifica-se, primeiramente, em função de que o estado do Maranhão e Grão-Pará constituía-se em uma região diversificada ecológica e geograficamente. Assim, a partir de uma perspectiva histórica, as razões para que os luso-americanos povoassem os vários espaços desse estado foram distintas e estavam relacionadas com múltiplos interesses. Ou seja, o povoamento do estado do Maranhão e Pará foi marcado pela heterogeneidade (Melo, 2017), e analisar essa diversidade é fundamental para refletir sobre a ideia de Amazônia.

Por outro lado, os discentes do curso se tornarão professores de história. Ao analisar o ensino de história, Vilma Barbosa (2006, p. 66) argumenta que o ensino de história local é importante "pela possibilidade de introduzir e de prenunciar a formação de um raciocínio histórico que contemple não só o indi- 
víduo, mas a coletividade, apreendendo as relações sociais que ali se estabelecem, na realidade mais próxima".

Dessa maneira, ainda que a autora utilize a expressão história local, sua ideia pode ser pensada também para a história regional. A utilização da história local e regional pelos professores pode ser fundamental, assim, para o desenvolvimento de sujeitos ativos e críticos, favorecendo o conhecimento de experiências coletivas ou individuais de um espaço, bem como da realidade mais próxima a ele. Por essa razão, é importante que os alunos do curso de história, como futuros docentes, tenham acesso também às discussões sobre a história da região, tanto da Amazônia, como ampla região, quanto do Baixo Amazonas.

Em grande medida, a produção historiográfica que analisa a Amazônia é feita a partir de discussões temáticas. Entre os variados temas analisados por essa historiografia, podem-se destacar os indígenas coloniais (Ferreira, 2016; Almeida, 1988; Amoroso, 1992; Araújo, 2014; Arenz, 2014; Bombardi, 2014; Cardoso, 2007; Carvalho Júnior, 2005; Cunha, 2012; Dias, 2011, p. 87-127; Domingues, 2000; Neves, 2012; Roller, 2013; Sampaio, 2007, 2012), a presença negra na Amazônia e o tráfico de africanos que foram escravizados (Barbosa, 2009; Bezerra Neto, 2001; Chambouleyron, 2006; Sampaio, 2011; Silva, 2012), o poder local (Corrêa, 2012; Dias, 2008; Feio, 2013) e as justiças eclesiástica e inquisitorial (Carvalho, 2018; Ferreira, 2017; Mattos, 2009; Mello, 2009).

Há, igualmente, uma historiografia que analisa as relações sociais construídas nas fronteiras da Amazônia portuguesa com as conquistas de outros reinos (Bastos, 2017; Brito, 2016) e que discute a ocupação do estado do Maranhão e Grão-Pará (Chambouleyron, 2010, p. 77-114), articulando às discussões acerca da constituição de fronteiras (Almeida, 2018; Dias, 2016; Melo, 2017; Roland, 2018; Souza, 2016). Essa produção historiográfica sobre o povoamento luso-americano do estado do Maranhão e Grão-Pará concentrou sua análise nas regiões das capitanias do Maranhão e Piauí, no leste da capitania do Pará, em áreas próximas à cidade de Belém e na ilha do Marajó. São escassas, contudo, as pesquisas que analisam a expansão luso-americana na região do Baixo Amazonas.

A reflexão sobre o que é a região amazônica e sobre como ela se cons titui deve ser feita também pelas discussões sobre a maneira pela qual foram se formando os espaços internos dessa região e como eles estavam, possivelmente, conectados e articulados. Como lembrou Soja, o espaço é primordialmente dado, porém a organização, o uso e o sentido que lhe são conferidos são decorrentes “de uma tradução, uma transformação e uma experiência sociais" (Soja, 1980 , p. 210). 
As missões religiosas e as fortalezas constituem dois entre vários mecanismos usados pela coroa portuguesa para conquistar e dominar um espaço. Em diversas áreas do rio Amazonas, foram edificadas missões religiosas. Entre as missões construídas na região do Baixo Amazonas, podemos destacar a de Gurupatuba (que se tornou a vila e depois a cidade de Monte Alegre), a do Tapajós (localizada na foz do rio Tapajós, onde se encontra a cidade de Santarém) e a missão de Nossa Senhora da Assunção dos Arapiuns (que se tornou Vila Franca). Além dessas e de outras missões, na região do Baixo Amazonas também foram edificadas três fortificações: o Forte do Tapajós, o de Nossa Senhora do Bom Sucesso do Paru (Forte da Vila de Almerim) e o de Santo Antônio dos Pauxis de Óbidos (Costa, 2014).

A organização das missões e a construção das fortificações não deixam de representar uma nova forma de organização do espaço pelo reino português. Esses mecanismos, juntamente com as diversas tropas que percorriam os rios da região, representam novas maneiras de se relacionar com o espaço e ensejaram a formação de novos territórios. Além disso, as próprias relações interétnicas foram modificadas. Com base nisso, por exemplo, Mark Harris (2015) discute como na região entre os rios Tapajós e Madeira configurou-se uma zona tribal, na qual as relações étnicas foram reconfiguradas, no final do século XVII, a partir das ameaças que outros grupos indígenas e os europeus ofereciam.

Esses núcleos coloniais, por sua vez, não viviam isolados. A agricultura, por exemplo, era essencial para a reprodução da vida material dos moradores das missões religiosas. Essa produção era direcionada ao abastecimento dessas missões e consistia em um dos subsídios para as expedições que se deslocavam ao sertão. Assim, esses aldeamentos espalhados pelos rios do estado do Maranhão e Grão-Pará não somente estabeleciam trocas entre si, como eram também entrepostos para as expedições que iam ao sertão (Ravena e Marin, 2013).

De fato, ainda que a produção econômica da Amazônia seja frequentemente associada às atividades extrativistas, a agricultura teve sua importância na conquista e na dominação do espaço. Uma dessas produções agrícolas está relacionada com as roças de farinha de mandioca. Como lembrou Roberto Cruz (2011, p. 39), a farinha foi significativa para a manutenção e a dominação do estado do Maranhão e Grão-Pará, que posteriormente se transformou em estado do Grão-Pará e Maranhão.

Uma carta de João Francisco Furtado trata justamente das roças e da produção de farinha na vila de Alter do Chão. O dito João Francisco Furtado, no ano 1763, escreveu de Alter do Chão para o governador do Estado do 
Grão-Pará e Maranhão, explicando-lhe que, "pela falta de farinhas que há nesta povoação" e por "ver que não podia achar na mesma povoação", teria mandado resgatar "pelas vilas vizinhas por panos e ferramentas". Esclarecia João Francisco Furtado que, ainda que tenha mandado fazer roças todos os anos, como the tinha sido ordenado, e "conforme a possibilidade do tempo que os índios tem nesta povoação", os "verões e as formigas as não deixam produzir" (Arquivo Público do Estado do Pará, cód. 131, doc. 70).

A farinha foi, igualmente, assunto de correspondência enviada a Manuel Bernardo de Melo e Castro, governador do Estado do Grão-Pará e Maranhão, por Inácio de Castro Sarmento. Na carta de 24 de maio de 1761, Castro Sarmento explicava a Melo e Castro que no dia 18 de maio tinham chegado a Santarém duas canoas do rio Negro para buscar farinha, e que "uma levou deste armazém duzentos e seis paneiros" e terminou "de carregar aos Pauxis" (Arquivo Público do Estado do Pará, cód. 106).

Os dois exemplos apontam para várias dimensões: o consumo e a circulação da farinha pela população da região amazônica, o modo como os núcleos coloniais situados no Baixo Amazonas podiam conectar-se, a utilização da agricultura nesses povoados e as dificuldades que poderiam ter para desenvolver essa prática. Remetem, assim, ao uso que era feito de um espaço e às dinâmicas de trocas e circulação de mercadorias, que são fundamentais para pensar a constituição de um espaço.

Ao analisar as salinas reais, nas proximidades da aldeia de Maracanã, e o pesqueiro, na ilha Grande de Joanes, Marina Hungria Nobre (2017, p. 26) lembra que, tão importantes quanto a farinha, as salinas e o pesqueiro real representavam estratégias de domínio sobre os espaços, assegurando a defesa da conquista, a produção e o abastecimento sistemáticos de gêneros, bem como o domínio sobre a mão de obra indígena. Um desses pesqueiros estava localizado no Baixo Amazonas. José Antonio Sotto Maior escreveu ao governador João Pereira Caldas, em setembro de 1774, explicando que os índios Mura aproximaram-se do "pesqueiro real chegando a cometer vários insultos quase na vizinhança dos Pauxis" (Arquivo Público do Estado do Pará, cód. 73).

É provável, por um lado, que o pesqueiro real, localizado no Baixo Amazonas, tivesse objetivos semelhantes ao da ilha de Joanes. Ou seja, é plausível que ele tenha sido edificado com a finalidade de abastecimento, defesa e domínio da área localizada mais a oeste do Estado do Grão-Pará e Maranhão. Nesse sentido, ainda que estivesse conectado à cidade de Belém, capital desse Estado, a construção de um pesqueiro no Baixo Amazonas pode sugerir que foi 
se constituindo uma área de abastecimento a partir dele que talvez não contemplasse todo o estado do Grão-Pará e Maranhão.

As missões religiosas e as fortificações representaram, de fato, mecanismos de ocupação de uma área. Porém, esse povoamento também é feito a partir do aproveitamento econômico do espaço. A prática agrícola, a produção da farinha e as atividades do pesqueiro real representavam meios também de apropriação do espaço. Além disso, o próprio abastecimento e a circulação da farinha e da produção do pesqueiro, bem como os conflitos com os índios, ajudam a pensar como se constituíram a dominação e a conquista lusitana no Baixo Amazonas.

É claro que, para a região do Baixo Amazonas, esses não foram os únicos mecanismos de conquista do espaço. Aqui, contudo, utilizo-os como exemplo para apontar a necessidade de analisar a história da Amazônia também a partir da constituição dos espaços localizados nas áreas mais afastadas dos centros de poder, como o Baixo Amazonas.

Por outro lado, a construção de espaços na região do Baixo Amazonas é, igualmente, produzida a partir da relação que os luso-americanos e indígenas construíram com os rios. O rio é, simultaneamente, universal, pois existem rios em todos os lugares e individualizados, uma vez que a relação que se constrói com ele é histórica e cultural (Sousa Neto, 1997, p. 65). Assim, são vários os rios e múltiplas as formas de apropriação simbólica e material (Chiapetti e Chiapetti, 2011, p. 72).

Dessa maneira, o processo de ocupação luso-americana da região amazônica ocorreu, em grande medida, pela construção de missões religiosas, fortalezas e vilas nas margens dos rios. Os rios foram utilizados como vias de circulação de pessoas e mercadorias e de fornecimento de alimentos. Nesse sentido, analisar a maneira como se constituiu um espaço na Amazônia demanda, igualmente, refletir sobre as múltiplas relações que as populações dessa região tinham com os rios. Certamente, estes tinham significados e usos distintos para os índios, para os luso-americanos e para a população negra.

\section{Considerações finais}

José d'Assunção Barros (2006) discorre sobre os riscos existentes quando o historiador associa seu espaço historiográfico a uma região administrativa, estatal ou geográfica, no sentido tradicional, pois os objetos historiográficos nem sempre se ajustam a esses limites. Um recorte regional deve ser feito a par- 
tir das perguntas que uma pesquisa se propõe responder. Assim, a delimitação espacial pode ser feita a partir de diversos critérios.

Durante o texto, utilizei a ideia de região associada à definição do que é o Baixo Amazonas, uma vez que se refere a um espaço situado no interior da vasta região amazônica. A proposta não é argumentar que esse espaço já se constituía em uma região, com uma dinâmica e identidade própria, desde a ocupação luso-americana. Não estou defendendo a construção de uma história colonial do Baixo Amazonas. É provável que as diversas relações construídas nessa região, atualmente, fossem diferentes das que foram construídas durante o período colonial.

A utilização de um recorte regional definido pela categoria Baixo Amazonas foi um mecanismo, portanto, utilizado para delimitar um espaço tratado neste texto e apontar a necessidade de desenvolver pesquisas regionais sobre a Amazônia colonial que contemplem os espaços mais afastados dos principais centros de poder, como Belém e São Luís. Desenvolver pesquisas com recortes regionais acerca dos espaços que hoje estão inseridos na área do Baixo Amazonas, sem estar necessariamente circunscrito a essa delimitação regional contemporânea, pode contribuir para refletir acerca da complexidade e da diversidade econômica, social e cultural da Amazônia, fazendo com que os alunos compreendam que são sujeitos históricos.

\section{Referências}

ALBUQUERQUE JUNIOR, Durval M. O objeto em fuga: algumas reflexões em torno do conceito de região. Fronteiras, Dourados, v. 10, n. 7, p. 55-67, jan./ jun. 2008.

ALMEIDA, Maria Regina C. de. Trabalho compulsório na Amazônia: séculos XVII-XVIII. Revista Arrabaldes, Rio de Janeiro, n. 2, p. 101-117, set./dez. 1988.

ALMEIDA, Rozemberg. Ocupação, colonização e relações de trabalho em Ourém do Grão-Pará (1751-1798). 2018. 115 f. Dissertação (Mestrado em História) — Programa de Pós-graduação em História Social da Amazônia, Universidade Federal do Pará, Belém, 2018.

AMOROSO, Marta. Corsários no caminho fluvial: os mura do rio Madeira. In: CUNHA, Manuela Carneiro da (org.). História dos índios no Brasil. São Paulo: Companhia das Letras, 1992. 
ARAÚJO, Alik N. de. De bárbaros a vassalos: os índios mura e as representações coloniais no oeste Amazônico (1714-1786). 2014. 149 f. Dissertação (Mestrado em História) - Programa de Pós-graduação em História Social da Amazônia, Universidade Federal do Pará, Belém, 2014.

ARENZ, Karl H. Além das doutrinas e rotinas: índios e missionários nos aldeamentos jesuíticos da Amazônia portuguesa (séculos XVII e XVIII). Revista História e Cultura, Franca, v. 3, n. 2, p. 63-88, 2014.

BARBOSA, Benedito C. C. Em outras margens do Atlântico: tráfico negreiro para o Estado do Maranhão e Grão-Pará (1707-1750). 2009. 152f. Dissertação

(Mestrado em História) — Programa de Pós-graduação em História Social da Amazônia, Universidade Federal do Pará, Belém, 2009.

BARBOSA, Vilma de L. Ensino de história local: redescobrindo sentidos. Saeculum, João Pessoa, n. 15, p. 57-85, jul./dez. 2006.

BARROS, José D’ Assunção. História, região e espacialidade. Revista de História Regional, v.10, n. 1, 95-129, 2006.

BASTOS, Carlos A. No limiar dos impérios. A fronteira entre a capitania do rio Negro e a provincia de Maynas: projetos, circulações e experiências (c. 1780-1820). São Paulo: Hucitec, 2017.

BEZERRA NETO, José Maia. A escravidão negra no Grão-Pará: séc. XVII e XIX. Belém: Paka-Tatu, 2001.

BOMBARDI, Fernanda A. Pelos interstícios do olhar do colonizador: descimentos de índios no estado do Maranhão e Grão-Pará (1680-1750). 2014. 188 f. Dissertação (Mestrado em História Social) — Programa de Pós-graduação em História Social, Universidade de São Paulo, São Paulo, 2014.

BRITO, Adilson J. I. Insubordinados sertões: o Império português entre guerras e fronteiras no norte da América do Sul - estado do Grão-Pará, 1750-1820. 2016. 589 f. Tese (Doutorado em História Social) - Faculdade de Filosofia, Letras e Ciências Humanas, Universidade de São Paulo, São Paulo, 2016.

CARDOSO, Alírio. Letras gentílicas: a arte da escrita e os índios da Amazônia (século XVII). In: FONTES, Edilza Joana de Oliveira; BEZERRA NETO, José Maia (org.). Diálogos entre história, literatura e memória. Belém: Paka-Tatu, 2007.

CARVALHO, Leila A. de. Os cadernos do promotor: as ações do Tribunal do Santo Ofício no Maranhão e Grão-Pará (1640-1750). 2018. 183 f. Dissertação (Mes- 
trado em História) — Programa de Pós-graduação em História Social da Amazônia, Universidade Federal do Pará, Belém, 2018.

CARVALHO JÚNIOR, Almir Diniz de. Índios cristãos: a conversão dos gentios na Amazônia portuguesa (1653-1769). 2005. 407 f. Tese (Doutorado em História) - Departamento de História, Instituto de Filosofia e Ciências Humanas, Universidade de Campinas, Campinas, 2005.

CHAMBOULEYRON, Rafael. Escravos do Atlântico equatorial: tráfico negreiro para o estado do Maranhão e Pará (século XVII e início do século XVIII). Revista Brasileira de História, São Paulo, v. 26, n. 52, p. 79-114, dez. 2006.

. Povoamento, ocupação e agricultura na Amazônia colonial (1640-1706). Belém: Açaí: Programa de Pós-graduação em História Social da Amazônia (UFPA): Centro de Memória da Amazônia (UFPA), 2010.

CHIAPETTI, R. J. N.; CHIAPETTI, Jorge. A água e os rios: imagens e imaginário da natureza. Geograficidade, Niterói, v. 1, n. 1, p. 71-90, 2011.

CORRÊA, Helidacy M. M. Comunicação política, poderes locais e vínculos: a Câmara de São Luís do Maranhão e a política luso-imperial de conquista do espaço. Outros Tempos, São Luís, v. 9, n. 14, p. 121-135, 2012.

COSTA, Graciete G. Fortificações na Amazônia. Navigator, Rio de Janeiro, v. 10, n. 20, p. 109-118, 2014.

CRUZ, Roberto B. Farinha de "pau" e de "guerra": os usos da farinha de mandioca no extremo norte (1722-1759). 2011. 146 f. Dissertação (Mestrado em História) — Programa de Pós-graduação em História Social da Amazônia, Universidade Federal do Pará, Belém, 2011.

CUNHA, Jonas A. da. As letras humanas: os povos indígenas e o ensino da língua portuguesa na Amazônia pombalina (1751-1763). 2012. 183 f. Dissertação (Mestrado) - Instituto de Filosofia e Ciências Humanas, Programa de Pós-graduação em História Social da Amazônia, Universidade Federal do Pará, Belém, 2012.

DIAS, Camila L. Civilidade, cultura e comércio: os princípios fundamentais da política indigenista na Amazônia (1614-1757). 2011. Dissertação (Mestrado em História Social) - Programa de Pós-graduação em História Social, Universidade de São Paulo, São Paulo, 2011.

DIAS, Joel S. "Confuso e intrincado labirinto": fronteira, território e poder na ilha Grande de Joanes (séculos XVII e XVIII). 2016. 622 f. Tese (Doutorado em 
História) - Programa de Pós-graduação em História Social da Amazônia, Universidade Federal do Pará, Belém, 2016.

. Os "verdadeiros conservadores" do estado do Maranbão: poder local, redes de clientela e cultura política na Amazônia colonial (primeira metade do século XVIII). 2008. 325 f. Dissertação (Mestrado em História) — Programa de Pósgraduação em História Social da Amazônia, Universidade Federal do Pará, Belém, 2008.

DOMINGUES, Ângela. Os conceitos de guerra justa e resgate e os ameríndios do norte do Brasil. In: SILVA, Maria Beatriz Nizza da (org.). Brasil: colonização e escravidão. Rio de Janeiro: Nova Fronteira, 2000.

FEIO, David S. S. O nó da rede de "apaniguados": oficiais das câmaras e poder político no estado do Maranhão (primeira metade do século XVIII). 2013. 146 f. Dissertação (Mestrado em História) — Programa de Pós-graduação em História Social da Amazônia, Universidade Federal do Pará, Belém, 2013.

FERREIRA, André L. B. Nas malhas das liberdades: o Tribunal da Junta das Missões e o governo dos índios na capitania do Maranhão (1720-1757). 2017. 205 f. Dissertação (Mestrado em História) — Programa de Pós-graduação em História Social da Amazônia, Universidade Federal do Pará, Belém, 2017.

FERREIRA, Elias A. C. Oficiais canoeiros, remeiros e pilotos jacumaúbas: mão de obra indígena na Amazônia colonial portuguesa (1733-1777). 2016. 158 f. Dissertação (Mestrado em História) — Programa de Pós-graduação em História Social da Amazônia, Universidade Federal do Pará, Belém, 2016.

HARRIS, Mark. Sistemas regionais, relações interétnicas e movimentos territoriais: os tapajó e além na história ameríndia. Revista de Antropologia, São Paulo, v. 58, n. 1, p. 33-68, 2015.

MATTOS, Yllan de. A última Inquisição: os meios de ação e funcionamento da Inquisição no Grão-Pará pombalino (1763-1769). 2009. 233 f. Dissertação (Mestrado em História) — Programa de Pós-graduação em História, Universidade Federal Fluminense, Niterói, 2009.

MELLO, Márcia E. A. de S. e. O regimento das missões: poder e negociação na Amazônia portuguesa. Clio. Série História do Nordeste, Recife, n. 27-1, p. 46-75, 2009.

MELO, Vanice S. de. "Aleivosias, mortes e roubos": guerras entre índios e portugueses na Amazônia colonial (1680-1706). 2008. 101 f. Monografia (Bacharela- 
do e Licenciatura em História) - Faculdade de História, Universidade Federal do Pará, Belém, 2008.

. Cruentas guerras: índios e portugueses nos sertões do Maranhão e Piauí (primeira metade do século XVIII). Curitiba: Prismas, 2017.

NEVES, Tamyris M. O lícito e o ilícito: a prática dos resgates no estado do Maranhão na primeira metade do século XVIII. Revista Estudos Amazônicos, Belém, v. VII, n. 1, p. 253-273, 2012.

NOBRE, Marina H. "Para o governo de sal e tainhas e de indios": as salinas e o pesqueiro real no estado do Maranhão e Pará (1640-1750). 2017. 130 f. Dissertação (Mestrado em História) — Programa de Pós-graduação em História Social da Amazônia, Universidade Federal do Pará, Belém, 2017.

RAVENA, Nirvia; MARIN, Rosa Elizabeth A. A teia de relações entre índios e missionários: a complementaridade vital entre o abastecimento e o extrativismo na dinâmica econômica da Amazônia Colonial. Varia História, Belo Horizonte, v. 29, n. 50, p. 395-420, ago. 2013.

ROLAND, Samir. Sesmarias, indios e conflitos de terra na expansão portuguesa no vale do Parnaíba (Maranbão e Piauí, séculos XVII e XVIII). 2018. 263 f. Dissertação (Mestrado em História) - Programa de Pós-graduação em História Social da Amazônia, Universidade Federal do Pará, Belém, 2018.

ROLLER, Heather Flynn. Expedições coloniais de coleta e a busca por oportunidades no sertão amazônico c. 1750-1800. Revista de História, São Paulo, n. 168, p. 201-243, jan./jun. 2013.

SAMPAIO, P. M. M. Espelhos partidos: etnia, legislação e desigualdade na colônia. Manaus: Edua, 2012.

. O fim do silêncio: presença negra na Amazônia. 1. ed. Belém: Açaí, 2011.

SAMPAIO, P. M. M. "Vossa Excelência mandará o que for servido...": políticas indígenas e indigenistas na Amazônia portuguesa do final do século XVIII. Tempo, Niterói, v. 12, n. 23, p. 39-55, 2007.

SILVA, Marley A. S. da. A extinção da Companbia de Comércio e o tráfico de africanos para o estado do Grão-Pará e Rio Negro (1777-1815). 2012. 127 f. Dissertação (Mestrado em História) - Programa de Pós-graduação em História Social da Amazônia, Universidade Federal do Pará, Belém, 2012. 
SOJA, Edward J. The socio-spatial dialectic. Annals of the Association of American Geographers, v. 70, n. 2, p. 207-225, jun. 1980.

SOUSA NETO, M. F. de. Três rios. Três regiões. Três poetas. GEOUSP, São Paulo, n. 1, p. 57-64, 1997.

SOUZA, Sueny D. O. de. Usos da fronteira: terras, contrabando e relações sociais no Turiaçu (Pará - Maranhão, 1790-1852). 2016. 206 f. Tese (Doutorado em História) - Programa de Pós-graduação em História Social da Amazônia, Universidade Federal do Pará, Belém, 2016.

UNIVERSIDADE FEDERAL DO OESTE DO PARÁ (UFOPA). Projeto político pedagógico do curso de licenciatura em história. Santarém, 2017. Disponível em: <http://www2.ufopa.edu.br/ufopa/arquivo/proen-cursos-portarias-ppcs/ppclicenciatura-historia/view.> Acesso em: 12 jun. 2019.

VISCARDI, Cláudia M. História, região e poder: a busca de interfaces metodológicas. Locus, Revista de História, Juiz de Fora, v. 3, n. 1, p. 84-97, 1997.

\section{Fontes}

ARQUIVO PÚBLICO DO ESTADO DO PARÁ. Carta de José Antonio Sotto Maior para João Pereira Caldas. Santarém, 2 maio 1774, cód. 73.

ARQUIVO PÚBLICO DO ESTADO DO PARÁ. Carta de João Francisco dos Santos para Manuel Bernardo de Melo e Castro. Alter do Chão, 25 out. 1763, cód. 131, doc. 70 .

ARQUIVO PÚBLICO DO ESTADO DO PARÁ. Carta de Inácio de Castro Sarmento para Manuel Bernardo de Melo e Castro. Santarém, 24 maio 1761, cód. 106. 